\title{
Acute lymphoblastic leukaemia under 2 years
}

\author{
A D LEIPER AND J CHESSELLS
}

Department of Haematology/Oncology, The Hospital for Sick Children, London

SUMmaRy Presenting features and natural history were assessed in 48 children with acute lymphoblastic leukaemia less than 2 years of age at diagnosis. Of these, 16 were less than 1 year (group 1) and 32 were between 1 and 2 years (group 2). Results were compared with a group of 348 children between the ages of 2 and 14 years (group 3) diagnosed over the same period.

The children in group 1 presented with a higher prevalence of null cell acute lymphoblastic leukaemia, leucocyte counts $>100 \times 10^{9} / 1$, and hepatosplenomegaly and had a higher central nervous system (CNS) relapse rate and shorter duration of remission than those in the other two groups. Disease free survival and overall survival in group 2 paralleled that of group 3, although children in group 2 had a significantly higher CNS relapse rate.

Neurological toxicity resulting from treatment with methotrexate and radiation was common in those under 2 years as a whole.

In conclusion, children under 1 year have a particularly poor prognosis, while those between 1 and 2 years have a prognosis similar to that in the older age group. Alternative approaches to CNS prophylaxis are needed to reduce the high prevalence of CNS disease and toxicity.

It has been recognised for some time that infants with acute lymphoblastic leukaemia, less than 2 years of age at presentation, tend to have a worse prognosis than older children. ${ }^{1-3}$

It has been suggested that babies presenting with acute lymphoblastic leukaemia under 1 year do particularly badly. ${ }^{4-6}$ We have examined the outcome in a group of infants less than 2 years of age diagnosed between 1972 and 1980 at our hospital, comparing in particular the clinical features and survival of those under 1 year with those aged between 1 and 2 years. Data for children aged between 2 and 14 years, presenting over the same period, have been included in this study for comparison.

\section{Patients and methods}

Three hundred and ninety six children presented to our hospital with acute lymphoblastic leukaemia between 1972 and 1980 . Forty eight were less than 2 years of age, of whom 16 were less than 1 year (group 1) and 32 between 1 and 2 years (group 2). The remainder (348) were between 2 and 14 years (group 3). There were eight boys in group 1, 17 in group 2, and 205 in group 3. The patients were treated on a number of protocols designed or being piloted for the Medical Research Council (MRC) working party on childhood leukaemia (UKALL), most of which have been reported elsewhere. ${ }^{7}$ All comprised multiple agent induction with at least three drugs, usually prednisolone, vincristine, and L-asparaginase, and continuing multiple agent chemotherapy for two to three years. Dosage modification during induction did not occur in any patient.

Central nervous system (CNS) prophylaxis consisted of $24 \mathrm{~Gy}$ of cranial irradiation before 1979 and 18 Gy thereafter and regular intrathecal methotrexate until completion of radiotherapy. Cranial irradiation was given as soon as complete remission was achieved in 24 children under the age of 2 years, and it was electively deferred until 2 years in a further 18, prophylaxis being continued in the intervening period with regular intrathecal methotrexate. Deferral of radiation became the consistent policy from 1978 onwards. Four of the latter 18 infants, although electively deferred, never received radiation: three died before the age of 2 and one developed methotrexate encephalopathy. A further six children did not receive irradiation because of very early deaths or failure to achieve remission.

Various presenting features were assessed in the three age groups and the results compared. All 
patients were followed up for a minimum of five years. The following features were chosen, the first two having prognostic importance. ${ }^{238}$

(1) Height of initial white blood cell count, classified as $<20 \times 10^{9} / 1,20-100 \times 10^{9} / 1$, and $>100 \times 10^{9} / 1$.

(2) Organ involvement. The presence of hepatomegaly, splenomegaly, lymphadenopathy, and a mediastinal mass was documented. Hepatomegaly and splenomegaly were termed 'massive' if below the umbilicus.

(3) Immunological surface markers. The leukaemia was classified into phenotypic subclasses using standard techniques and definitions previously described by Greaves et al. ${ }^{9}$ Acute lymphoblastic leukaemia was thus divided into the four following types: common (ALL) $\left(\mathrm{cALLA}{ }^{+}, \mathrm{la}^{+} \mathrm{Tdt}^{+}\right), \mathrm{T}$ cell $(\mathrm{T}-\mathrm{ALL})$ (E-rosette $\left.{ }^{+} \mathrm{la}^{-}, \mathrm{Tdt}^{+}\right)$, null cell (null-ALL) (cALLA ${ }^{-}, \mathrm{la}^{+} \mathrm{Tdt}^{+}$), and B cell (B-ALL) $\left(\mathrm{Smlg}^{+}, \mathrm{cALLA}^{-}, \mathrm{la}^{+} \mathrm{Tdt}^{-}\right)$.

Statistical methods. Statistical methods used were Fisher's exact probability test and the $\chi^{2}$ test. Survival curves were compared using the log rank test.

\section{Results}

Presenting features. Presenting features in the three age groups are shown in Table 1.

(i) White blood cell count

The proportion of babies in Group 1 who had a

Table 1 Presenting features in children with acute lymphoblastic leukaemia, relating to the three age groups

\begin{tabular}{llll}
\hline Presenting feature & \multicolumn{2}{l}{ Age group } & \\
\cline { 2 - 4 } & $\begin{array}{l}1(<1 \text { year }) \\
(n=16)\end{array}$ & $\begin{array}{l}2(1-2 \text { years }) \\
(n=32)\end{array}$ & $\begin{array}{l}3(2-14 \text { years }) \\
(n=348)\end{array}$ \\
\hline White blood cell & & & \\
count $\left(\times 10^{9} / l\right)$ & & & \\
$<20$ & 5 & 19 & 233 \\
$20-100$ & 3 & 9 & 80 \\
$>100$ & 8 & 4 & 35 \\
Organomegaly & & 27 & 207 \\
Hepatomegaly & 16 & 25 & 265 \\
Splenomegaly & 16 & 22 & 33 \\
Lymphadenopathy & 12 & & 166 \\
Mediastinal mass & 0 & 17 & 14 \\
Immune type & & 2 & 73 \\
Common & 4 & 1 & 125 \\
Null cell & 5 & 0 & \\
T cell & 0 & 12 & \\
B cell & 0 & & \\
Dubious or not & 7 & & \\
$\quad$ tested & & &
\end{tabular}

white blood cell count $>100 \times 10^{9} / 1$ was significantly higher than in groups $2 \quad(p=0.009)$ and 3 $(p=<0.001)$. The difference between groups 2 and 3 was not significant. The number of patients who had a white blood cell count between 20 and $100 \times 10^{9} / 1$ was similar in all groups, while only a third of those in group 1 had a count $<20 \times 10^{9} / 1$.

\section{(ii) Organ involvement}

The prevalence of hepatomegaly in groups 1 and 2 was not significantly different, but there was a much higher prevalence in these two groups compared with group $3(p=0.001$ and 0.005 , respectively). None had hepatomegaly below the umbilicus. All 16 babies in group 1 had splenomegaly, of whom five had massive spleens extending below the umbilicus. Although the total prevalence was not significantly different from group 2, none of the latter group had massive splenomegaly. The prevalence of splenomegaly in group 1 was significantly higher than group $3(p=0.002)$, but there was no difference between groups 2 and 3 .

\section{(iii) Immunological markers}

Fifty six per cent of the patients tested in group 1 , $10 \%$ of those tested in group 2 , and $6 \%$ of those tested in group 3 had null-ALL. Although we were unable to apply statistical tests to these results in view of their incomplete nature, null-ALL seemed

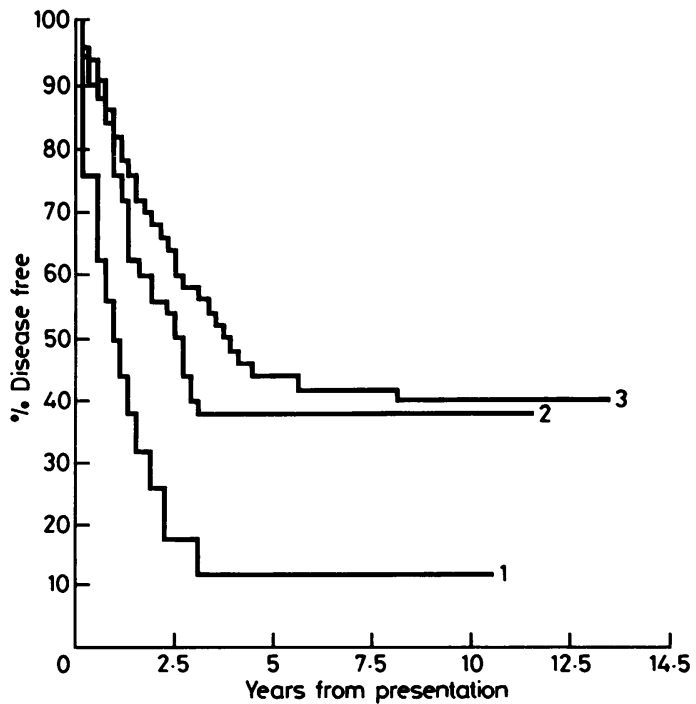

Fig. 1 Life table showing disease free survival in the three age groups (group 1 aged $<1$ year, group 2 aged $1-2$ years, and group 3 aged 2-14 years) of children with acute lymphoblastic leukaemia. 
to be more common in group 1 than in groups 2 and 3 . Less than half of those tested in group 1 had common ALL. No child under 2 years had B-ALL, and only one had T-ALL.

\section{Natural history.}

(i) Remission induction and disease free survival Of the 48 patients aged less than 2 years, $45(94 \%)$ achieved remission using standard induction chemotherapy without modification of dosage. This compared with $97 \%$ of those achieving remission in group 3 . Of the two patients in group 1 and one in group 2 who did not achieve remission, two died of sepsis and one of haemorrhage secondary to leucostasis.

Figure 1 shows the disease free survival in the three groups. There was a highly significant difference between groups 1 and $2(p=0.01)$ and groups 1 and $3(p=0.01)$ but no significant difference between groups 2 and 3 . The median duration of remission in group 1 was 10 months compared with 29 months in group 2 and 41 months in group 3 .

\section{(ii) Survival}

Overall survival is shown in Table 2. This was significantly higher in groups 2 and 3 than in group 1 $(p=0 \cdot 009)$. There was no significant difference in the duration of survival of children in groups 2 and 3 . Two girls are still alive from group 1, both in their first remission, 42 and 116 months from diagnosis. Fourteen children (nine boys and five girls) are still alive from group 2, 12 in their first remission, between 39 and 127 months from diagnosis. No patient in group 1 and only one in group 2 with white blood cell count at diagnosis greater than $100 \times 10^{9} / 1$ has survived. Deaths in complete remission are shown in Table 2.

(iii) Relapse

Table 2 shows bone marrow and CNS relapse as first events in the three groups. The incidence of bone marrow relapse, including combined bone marrow

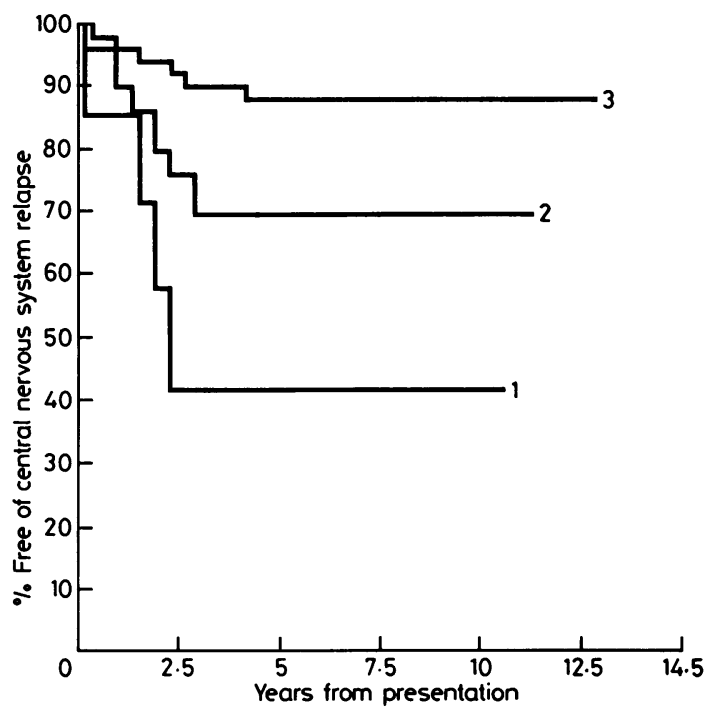

Fig. 2 Actuarial prevalence of central nervous system relapse in the three age groups (group 1 aged $<1$ year, group 2 aged 1-2 years, and group 3 aged 2-14 years) of children with acute lymphoblastic leukaemia.

Table 2 Table of first events and survival in children with acute lymphoblastic leukaemia in the three age groups

\begin{tabular}{|c|c|c|c|}
\hline & \multicolumn{3}{|l|}{ Age group } \\
\hline & $\begin{array}{l}l(<1 \text { year }) \\
(n=16)\end{array}$ & $\begin{array}{l}2(1-2 \text { years }) \\
(n=32)\end{array}$ & $\begin{array}{l}3(2-14 \text { years }) \\
(n=348)\end{array}$ \\
\hline \multicolumn{4}{|l|}{ Relapses } \\
\hline Bone marrow & 5 & 7 & 121 \\
\hline Central nervous system & 4 & 6 & 27 \\
\hline Testis & 0 & 0 & 21 \\
\hline No remission & 2 & 1 & 11 \\
\hline Death in complete remission & 1 (pneumocystis) & $\begin{array}{l}5 \text { (3 septicaemia, } \\
1 \text { measles, } \\
1 \text { viral pneumonia) }\end{array}$ & $\begin{array}{c}15 \text { (2 septicaemia, } \\
7 \text { measles. } \\
2 \text { cytomegalovirus, } \\
2 \text { encephalitis, } \\
1 \text { chickenpox, } \\
1 \text { mycoplasma) }\end{array}$ \\
\hline Survival & 2 & 14 & 186 \\
\hline
\end{tabular}


and extramedullary relapses, was $44 \%$ in group 1 compared with $25 \%$ in group 2 , which was significant $(p=0 \cdot 008)$. There was no difference between groups 2 and 3 . Figure 2 shows that the CNS relapse rate was significantly higher in groups 1 and 2 compared with group $3(\mathrm{p}=<0.0001$ and 0.03 , respectively). Although the incidence was higher in group 1 than in group 2, this difference did not reach significance.

Table 3 shows the number of patients suffering a CNS relapse in groups 1 and 2 in relation to the time at which cranial radiotherapy was given. When CNS relapse was related to the timing of cranial irradiation in groups 1 and 2 combined, we found that of the 18 patients in whom radiotherapy was deferred to the age of 2 years, six had isolated CNS relapses and one had a combined bone marrow, CNS, and testicular relapse. Three patients, all in group 1, relapsed in the CNS before receiving radiotherapy. Of the 24 patients receiving cranial radiotherapy soon after remission, four had isolated CNS relapses and a further two had combined relapses (bone marrow and CNS). All but one were in group 2. One patient relapsed before radiotherapy. The difference in incidence of CNS relapse using these two approaches was not significant, not did it depend on the dose of radiation received.

\section{(iv) Neurological complications}

The overall incidence of major neurological complications in patients less than 2 years was $17 \%$. Confirmed methotrexate encephalopathy occurred in four children (two in group 1 and two in group 2). Three of these had CNS leukaemia (two in group 1 and one in group 2), two of whom were treated with intrathecal methotrexate and craniospinal irradiation. Encephalopathy developed in the third in the absence of radiotherapy, which was therefore withheld. This child was 8 months of age at the time of his first CNS relapse. The remaining child who suffered encephalopathy in the absence of CNS leukaemia was 2 years old at the time of his radiotherapy. In addition, convulsions have occurred for the first time in one of the long term

Table 3 No of patients suffering a central nervous system relapse/total No of patients receiving radiotherapy in groups 1 and 2 in relation to timing of cranial radiotherapy

\begin{tabular}{lll}
\hline Group & \multicolumn{2}{l}{ Timing of radiotherapy } \\
\cline { 2 - 3 } & Deferred $^{*}$ & Earlyt \\
\hline 1 & $5 / 10$ & $1 / 3$ \\
2 & $2 / 8$ & $5 / 21$ \\
\hline
\end{tabular}

${ }^{*}$ Deferred $=$ until 2 years of age.

$\dagger$ Early $=$ on achieving remission. survivors from group 1 at 116 months from diagnosis. Computed tomography revealed calcification, which, although not diagnostic, is suggestive of methotrexate encephalopathy.

Intellectual impairment occurred in three survivors. One child was severely affected, with an intelligence quotient (IQ) of 50 and is also deaf. Two of the three, including this patient, received prophylactic irradiation when less than 2 years of age.

\section{Discussion}

Most reports state that children less than 2 years old at diagnosis have a worse prognosis than those diagnosed between the ages of 2 and 10 years. ${ }^{12}$ Our study seems to indicate, however, that these figures are heavily weighted by the cohort of infants less than 1 year of age, who fare particularly badly. Those aged 1-2 years seem to have survival curves very similar to those aged 2-14 years, despite the higher prevalence of CNS disease.

Babies under 1 year at diagnosis have a much higher prevalence at presentation of null cell leukaemia, white blood cell count $>100 \times 10^{9} / 1$, and splenomegaly extending below the umbilicus than either those between 1 and 2 years or those between 2 and 14 years. They also have a greater prevalence of hepatomegaly than the latter group. Their disease free and overall survival is significantly less than the other two groups, and they have a much higher prevalence of CNS disease, although this only reaches significance when compared with those patients over 2 years of age. This experience parallels that of other authors, ${ }^{25}$ although we did not find a high incidence of meningeal involvement at diagnosis. ${ }^{5}$

Early cytogenetic studies on the leukaemic clone of cells has only recently become routine at our hospital. The recent recognition of the (4:11) translocation ( $t 4: 11)$ in acute lymphoblastic leukaemia and its unsustained response to standard chemotherapy in young babies ${ }^{10} 11$ makes it likely that at least some of the infants included in our study have possessed these abnormal chromosomes, which may help to account for their poor survival. It has also been shown that children with t4:11 tend to present with the same features as we have found in our group of infants. Typically, the patients are less than 1 year of age, have high white blood cell counts at diagnosis, and do not express the common acute lymphoblastic leukaemia antigen. ${ }^{10}$ Their prognosis is poor.

Age is said to be an independent prognostic factor, ${ }^{46}$ but our finding of a number of poor prognostic features in infants in the first year of life, including hepatomegaly, massive splenomegaly, and 
high white blood cell count, ${ }^{34}$ makes it difficult to confirm such a statement. It has recently been suggested, however, that age of less than 6 months seems to be an independent prognostic variable. ${ }^{5}$

CNS disease is particularly prevalent in infants aged less than 2 years at diagnosis and especially so in infants aged less than 1 year. It was initially thought that the high prevalence of meningeal involvement might be due to the practice of deferring cranial irradiation until after the second birthday. It is true that more patients in group 2 had early radiation than in group 1 and that the prevalence of CNS disease is lower in this group, but none the less the percentage of patients relapsing in group 2 despite early radiotherapy is the same as in those in whom radiation was deferred. Certainly, when these two approaches were compared statistically the prevalence of CNS relapse did not differ significantly. A similar experience is shared by Reaman $e t$ $a l$, who found that there was no difference in CNS relapse rate between those in whom prophylaxis combined cranial radiation and intrathecal methotrexate and those in whom intrathecal methotrexate was used alone. ${ }^{5}$ It has been noted in our study, however, that more patients relapsed before receiving radiotherapy in the group of children in whom it was deferred $(16 \%)$ than in those who received early radiotherapy $(4 \%)$. These patients were all in group 1, and it may reflect an inherent propensity for early CNS disease in the very young.

The high prevalence of neurological complications found in our series of 48 patients under 2 years is perhaps not unexpected. Several studies have revealed that although most children have IQs within the normal range after treatment with standard CNS prophylaxis and oral methotrexate, those under 3 years at the time of radiation have significantly lower IQs than those treated at an older age. ${ }^{12-14}$ Moss et al also noted greater impairment in intellectual abilities in the youngest children. ${ }^{15}$ It is not surprising therefore that intellectual impairment was found in three children, two of whom received cranial irradiation under the age of 2 years. It is for this reason that our policy since 1978 has been to defer cranial irradiation until after the second birthday, and this also warrants alternative approaches such as triple intrathecal chemotherapy to decrease CNS morbidity. ${ }^{16}$

Methotrexate neurotoxicity is more commonly encountered in children with previous CNS leukaemia $^{17}$ where the cumulative dose of intrathecal methotrexate is high in combination with cranial radiotherapy. As the prevalence of CNS leukaemia is high in those aged under 2 years methotrexate encephalopathy is a real cause for concern. Indeed, we found that out of 13 children aged under 2 years who developed CNS disease, three developed severe methotrexate neurotoxicity. Two further children with fits and changes in their computed tomograms compatible with toxicity did not have CNS disease.

In summary, this study confirms suspicions that infants less than 1 year at presentation have a very poor prognosis, while those between 1 and 2 years show long term survival comparable to that of older children. Whether the outlook will be improved by more intensive chemotherapy remains unclear, but in view of the high prevalence of CNS disease and toxicity, alternative approaches to CNS prophylaxis need to be found.

\section{References}

1 George SL, Fernbach DJ, Vietti TJ, et al. Factors influencing survival in paediatric leukaemia: the SWCCSG experience. Cancer 1973;32:1542-53.

2 Cangir A, George S, Sullivan M. Unfavorable prognosis of acute leukaemia in infancy. Cancer 1975;36:1973-8.

${ }^{3}$ Hardisty RM, Till M. Factors affecting prognosis. Arch Dis Child 1968:43:107-15.

${ }^{4}$ Miller DR, Sandford C, Albo V, et al. Prognostic factors and therapy in acute lymphoblastic leukaemia of childhood: CCG 141-. Cancer 1983;51:1041-9.

5 Reaman G, Zelter P, Bleyer WA, et al. Acute lymphoblastic leukaemia in infants less than 1 year of age. A cumulative experience of the Childrens' Cancer Study Group. Journal of Clinical Oncology 1985;3:1513-21.

${ }^{6}$ Zippin C, Cutter SJ, Reeves WJ, et al. Variation in survival among patients with ALL. Blood 1971;37:59-72.

7 Chessells JM, Ninane J, Tiedeman K. Present problems in management of childhood lymphoblastic leukaemia. Experience from the Hospital for Sick Children, London. In: Neth R, Gallo RC, Graft T, Mannweiler R, eds. Modern trends in human leukaemia IV. Berlin: Springer-Verlag, 1981:108-14.

${ }^{8}$ Simone JV, Verzosa MS, Rudy JA. Initial features and prognosis in 363 children with acute lymphoblastic leukacmia. Cancer 1975;36:2099-108.

9 Greaves MF, Janossy G, Peto J, et al. Immunologically defined subclasses of acute lymphoblastic lcukaemia in children: their relationship to presentation features and prognosis. $\mathrm{Br}$. J Haematol 1981;48:179-97.

10 Secker Walker LM, Stewart EL, Chan L, et al. The (4:11) translocation in acute leukaemia of childhood: the importance of additional chromosomal aberrations. $\mathrm{Br} J$ Haematol 1985;61:101-11.

$"$ Arthur DC, Bloomfield CD, Lindquist LL, et al. Translocation t4:11 in ALL. Clinical characteristics and prognostic significance. Blood 1982;59:96-9.

12 Janoun L. Long term effects of childhood leukaemia. Cognitive deficits and educational attainment. Arch Dis Child 1983; 58:953-8.

${ }^{13}$ Eiser C. Intellectual ability among survivors of childhood leukaemia as a function of CNS irradiation. Arch Dis Child 1978;54:391-5.

14 Eiser C. Effects of chronic illness on intellectual development. A comparison of normal children with those treated for childhood leukaemia and solid tumours. Arch Dis Child 1980;55:766-70.

15 Moss HA, Nannis ED, Poplack DA. The effects of prophylactic 
treatment of the CNS on the intellectual functioning of children with ALL. Am J Med 1981;71:47-52.

16 Sullivan MP, Chan $T$, Dyment PG, et al. Equivalence of intrathecal chemotherapy and radiotherapy as central nervous system prophylaxis in children with acute lymphoblastic leukaemia: a paediatric oncology group study. Blood 1982;60:948-58.

17 Campbell RH, Marshall WC, Chessells JM. Neurological complications of childhood leukaemia. Arch Dis Child 1977;52:850-8.

Correspondence to Dr A D Leiper, Department of Haematology/ Oncology, Hospital for Sick Children, Great Ormond Street, London WC1N 3JH.

Received 27 June 1986

British Paediatric Association

Annual meetings

At York University:

1987 April 7-10

1988 April 12-16

1989 April 11-15

At University of Warwick:

1990 April 3-7

1991 April 16-20

1992 April 7-11

1993 April 19-23 (provisional)

1994 April 11-15 (provisional) 